\title{
Assessment of voice changes of patients after thyroidectomy without inferior and superior laryngeal nerves injury according to the intraoperative neuromonitoring
}

\author{
A Guillemaud ${ }^{1}$, G Buiret ${ }^{1 a^{*}}$, M Fieux ${ }^{2}, S$ Zaouche ${ }^{2 a}, J_{C}$ Lifante $^{3}$ \\ ${ }^{1}$ Service d'ORL et de chirurgie cervicofaciale, Centre Hospitalier de Valence, 179 Boulevard du Maréchal Juin, 26953 Valence, France. \\ ${ }^{2}$ Service d'ORL et de chirurgie cervicofacial, Centre Hospitalier Lyon Sud, Chemin du Grand Revoyet, 69495 Pierre-Bénite France. \\ ${ }^{3}$ Service de chirurgie viscérale et endocrinienne, Centre Hospitalier Lyon Sud, Chemin du Grand Revoyet, 69495 Pierre-Bénite France.
}

*Corresponding Author: G Buiret, Service d'ORL et de chirurgie cervicofaciale, Centre Hospitalier de Valence, 159 Boulevard du Maréchal Juin, 26953 Valence.

Received date: February 23, 2021 : Accepted date: April 26, 2021 : Published date: May 07, 2021

Citation: A Guillemaud, G Buiret, M Fieux, S Zaouche, JC Lifante. (2021) Assessment of voice changes of patients after thyroidectomy without inferior and superior laryngeal nerves injury according to the intraoperative neuromonitoring. 3(2); DOI: 10.31579/2692-9562/025

Copyright: @ 2021, G Buiret. This is an open access article distributed under the Creative Commons Attribution License, which permits unrestricted use, distribution, and reproduction in any medium, provided the original work is properly cited

\begin{abstract}
Objectives: to assess voice changes of patients after thyroidectomy without inferior and superior laryngeal nerves injury according to the intraoperative neuromonitoring.

Material and methods: This monocentric study included all patients who underwent thyroidectomy with laryngea nerves neuromonitoring between September, 2018 and December, 2019. The voice assessment was performed 1 month before and 3 months after surgery. It was both subjective (with Voice Handicap Index 10 and GRBAS scale) and objective (Dysphonia Severity Index). Voice was considered impaired if there was an increase $\geq 4$ points of the Voice Handicap Index 10 score or $\geq 1$ point of the GRBAS scale score or a decrease $\geq 2$ points of the Dysphonia Severity Index score between the two vocal assessments. A composite score was created, combining both subjective and objective scores Predictive factors of altered voice were seek.

Results: Fifty-nine patients were analyzed. Mean Voice Handicap Index 10 varied from $3.39 \pm 5.40$ to $2.90 \pm 5.29$ ( $\mathrm{p}=$ $0.62)$ before and after the surgery respectively, mean GRBAS from $0.64 \pm 0.76$ to $0.73 \pm 0.85(\mathrm{p}=0.57)$ and mean Dysphonia Severity Index from $8.47 \pm 1.15$ to $8.31 \pm 1.03(\mathrm{p}=0.42)$. Voice impairment composite score identified 14 patients with an impaired voice $(23.7 \%)$. Age $\geq 65$ years, preoperative Voice Handicap Index 10 score $\geq 3$ and thyroidectomy past history were independent risk factors of voice impairment.

Conclusions: the voice quality 3 months after thyroidectomy was not significantly subjectively and objectively chan ged compared to before thyroidectomy. When grouping voice impairment scores, age $\geq 65$ years, preoperative Voice Handicap Index 10 score $\geq 3$ and thyroidectomy past history were independent risk factors of voice impairment.
\end{abstract}

Key words: thyroidectomy; inferior laryngeal nerve; superior laryngeal nerve; voice quality

\section{Introduction}

In France, 49477 thyroidectomies were performed in 2014 [1]. The main and specific risk of this procedure is post-operative dysphony [2]. This procedure may be explained by a lesion of the lower laryngeal nerve resulting in vocal alteration by paralysis of the ipsilateral vocal cord. This complication incidence is estimated between 0 and $18.6 \%$ for an average value of $2.3 \%$ [3]. In the absence of injury to this nerve, post-operative vocal changes are regularly attributed to damage to the External Branch of the Upper Laryngeal Nerve (EBULN), whose incidence is estimated between 5 and $28 \%$ of thyroidectomies [2]. This branch, innerving the cricothyroid muscle, allows the vocal cords to be stretched during phonation. In case of injury, the symptoms described are variable and not specific: limitation or loss of singing voice, vocal weakness, decreased maximum phonation time, reduction of voice strength [4].
It is possible to monitor the laryngeal nerves (neuromonitoring) during the surgery. This tool is reliable. Indeed, the negative predictive value of intraoperative monitoring of lower laryngeal nerves is very high, between 92 and $100 \%$ [4]. Thus, a patient operated on from thyroidectomy should not have a post-operative laryngeal paralysis if the electrical signals of these nerves are preserved at the end of the procedure. In addition, this laryngeal monitoring can be used to help identify and preserve EBULN $[5,6]$. Stimulation of this nerve branch results in a glottic electrical response in 70 to $80 \%$ of cases [7]. However, the correlation between the absence of electrical (lower and upper) laryngeal nerves injury and quality of voice is not absolute and if the laryngeal monitoring allows to know post-operative cordal mobility, it does not guarantee the absence of alteration of the patient's vocal quality. Indeed, other causes of postthyroidectomy vocal impairment are classically advanced: laryngeal 
edema, any other post-intubation complication, muscle lesions (section or resection of an infrahyoid muscle, lesion of one cricothyroid muscle), changes in the vascularization or the lymphatic drainage of the larynx, post-operative pain itself, psychological impact of this surgery or hormonal changes secondary to the thyroidectomy [8].

Few studies focused on the evolution of the voice after thyroidectomy in patients without laryngeal nerve lesion according to neuromonotoring. The main objective of this work was to analyze the evolution of patients' voices after thyroidectomy using subjective and objective tools. The secondary objective of the study was to identify predictive factors of voice impairment when intraoperative electrical responses were normal.

\section{Methods}

We conducted a single-center descriptive study from September 2018 to December 2019.

\section{Recruiting}

In the endocrine surgery unit, patients for whom thyroid surgery is scheduled has a consultation with an ENT one month prior to surgery to control laryngeal mobility.

All patients who volunteered during this period to receive a voice recording during this consultation as well as 3 months after surgery were analyzed.
The inclusion criteria were: patients $\geq 18$ years-old, able to read French, and undergoing a thyroidectomy (partial or total, with or without associated recurrent or bilateral lymphadenectomy) with intraoperative monitoring of the lower and upper laryngeal nerves.

The non-inclusion criteria were: patients with preoperative laryngeal paralysis, an objectified cordal lesion at pre-surgical consultation or for whom an unrelated event interfered with speech-altering surgery occurred between preoperative consultation and surgery.

The exclusion criterion after surgery was the loss of the signal during lower laryngeal stimulation or the absence of a signal from one of the upper laryngeal nerves (true absence or missing signal data).

The study protocol was approved by the institutional review board and was conducted in accordance with the principles of the Declaration of Helsinki. All participants provided written informed consent before inclusion.

\section{Population}

Ninety-nine patients operated on from thyroid surgery received an ENT consultation with preoperative vocal check-ups. The flowchart of the study is shown in Figure 1. Among the eight patients with a lost of signal at the end of the surgery, only two had finally a laryngeal paralysis, all with thyroid carcinoma.

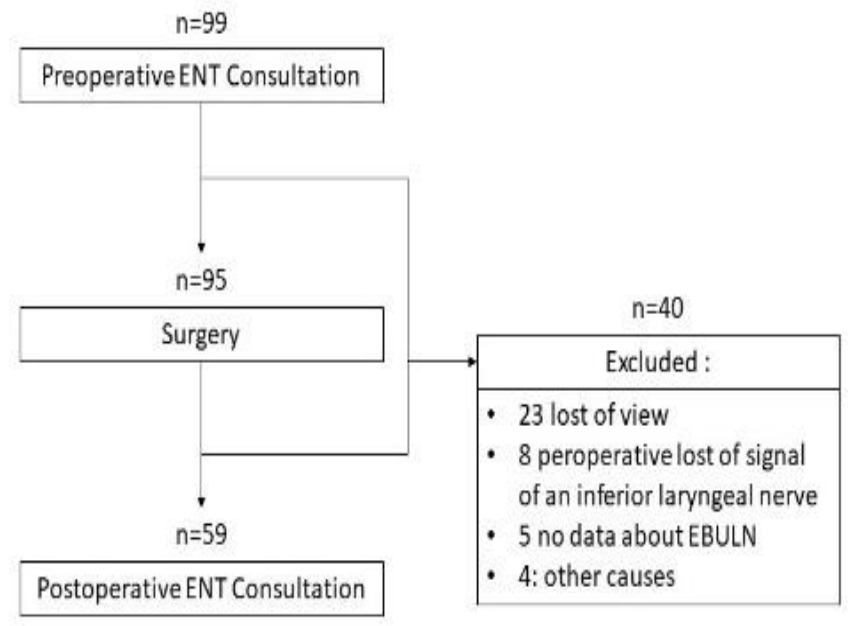

EBULN: External Branch of the Upper Laryngeal Nerve Figure 1. Flowchart of the study.

The mean age was 54 years \pm 14 . The sex-ratio was 3 women per 1 man, the mean body mass index was $26.05 \mathrm{~kg} / \mathrm{m}^{2} \pm 4.68$ and the mean follow- up time was 4 months. The population characteristics are presented in table 1.

\begin{tabular}{|l|l|}
\hline Characteristics & $\mathbf{n}(\boldsymbol{\%})$ \\
\hline Sex: & \\
\hline Females, n (\%) & $44(74.6)$ \\
\hline Males & $15(25.4)$ \\
\hline
\end{tabular}




\begin{tabular}{|c|c|}
\hline \multicolumn{2}{|l|}{ Intensive vocal use at work: } \\
\hline Yes & $34(57.6)$ \\
\hline No & $5(8.5)$ \\
\hline No information & $20(33.9)$ \\
\hline \multicolumn{2}{|l|}{ Smoking: } \\
\hline Yes & $12(20.3)$ \\
\hline No & $47(79.7)$ \\
\hline Cervical surgery past history & $6(10.2)$ \\
\hline Cause of surgery: & $7(11.9)$ \\
\hline Benign nodular goiter & $29(49.2)$ \\
\hline Goiter with thyrotoxicosis & $7(11.9)$ \\
\hline Suspect nodule & $10(16.9)$ \\
\hline Papillary carcinoma & $5(8.5)$ \\
\hline Hematocele & $1(1.7)$ \\
\hline \multicolumn{2}{|l|}{ Type of surgery: } \\
\hline Total thyroidectomy & $36(61.0)$ \\
\hline Lobo-isthmectomy & $11(18.6)$ \\
\hline Thyroidectomy and lymphadenectomy & $8(13.6)$ \\
\hline \multicolumn{2}{|l|}{ Associated muscle resection } \\
\hline Yes & $4(6.8)$ \\
\hline No & $55(93.2)$ \\
\hline \multicolumn{2}{|l|}{ Associated muscle section: } \\
\hline Yes & $13(22.0)$ \\
\hline No & $46(78.0)$ \\
\hline $\begin{array}{l}\text { Final pathological diagnosis: } \\
\text { Benign }\end{array}$ & $40(67.8)$ \\
\hline Malignant & $15(25.4)$ \\
\hline Other $^{\mathrm{a}}$ & $4(6.8)$ \\
\hline $\begin{array}{l}\text { Iodine therapy: } \\
\text { Yes }\end{array}$ & $5(8.5)$ \\
\hline No & $54(91.5)$ \\
\hline
\end{tabular}

Table 1. Population characteristics and perioperative data.

a Non-invasive vesicular tumour with papillary-type nuclei $(n=3)$ and thyroid metastasis of a neuroendocrine tumour $(n=1)$.

Surgical procedure

A

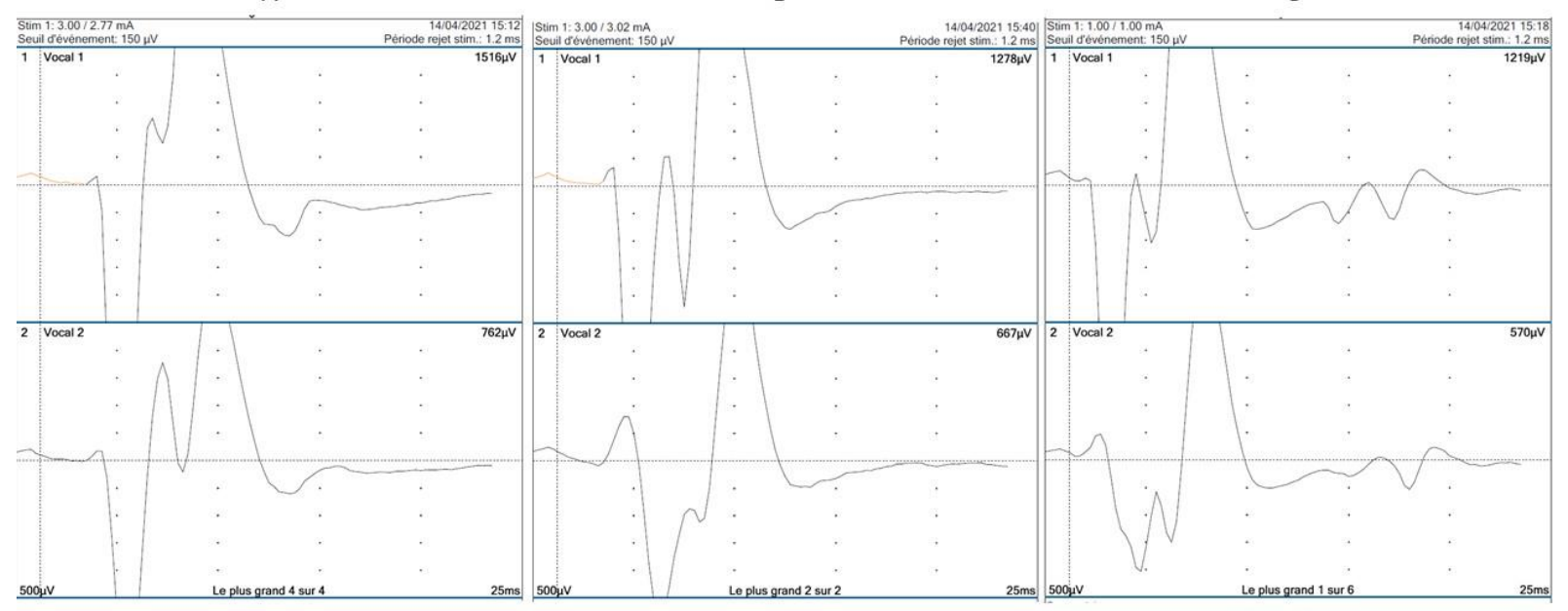

Nerve monitoring was carried out using Medtronic's NIM-Response 3.0 (Medtronic Xomed, Jacksonville, Florida, USA) in intermittent stimulation. The figure 2 presents the NIM and the expected reponses.

Figure 2: Medtronic NIM ${ }^{\circledR}$ and the expected laryngeal responses.

A: stimulation of vagus nerve before the inferior laryngeal nerve dissection; B: stimulation of vagus nerve after the inferior laryngeal nerve dissection; $\mathrm{C}$ : stimulation of the superior laryngeal nerve with collection of the signal of the inferior laryngeal nerve 
The lower laryngeal nerve in the reseated lobe was considered functional at the end of the procedure if it was macroscopically intact and its stimulation direct to $1 \mathrm{~mA}$ as well as that at $3 \mathrm{~mA}$ of the ipsilateral vagus nerve resulted in a normal-shaped glottic electrical response (biphasic curve), intensity and latency on neuromonitoring. The EBULN was considered functional if its direct stimulation at $1 \mathrm{~mA}$ resulted in a glottic electrical response on neuromonitoring or if a contraction of the cricothyroid muscle was observed with the naked eye.

If one of the four nerve branches (bilateral lower and upper laryngeals) was not considered intact, the patient was excluded from the study.

\section{Voice assessment}

The voice recording allowed subjective and objective analyses of the subjects' voices.

The subjective assessment of the voice was carried out by:

- A auto-assessment questionnaire: the Voice Handicap Index 10 (VHI 10) [9] that the patient had to complete after reading the text "The Wind and the Sun" (Annex 1). The VHI 10, a simplified version of the Voice Handicap Index in 30 questions (VHI 30), is a validated tool that allows the rapid and simple assessment of the quality of the voice and the impact of the voice on the patient's quality of life, as perceived by the patient. It is a questionnaire in 10 questions, from 0 to 4 points for each of them, with a total score ranging from 0 to 40 depending on the vocal discomfort. An asymptomatic patient will have a VHI 10 near 0 while a patient experiencing permanent vocal discomfort will have a score approaching 40.

- An hetero-assessment questionnaire: the GRBAS [10]. This acronym takes 5 characteristics of a voice: its "Grade", its raucous ("Rough"), its veiled character ("Breathy"), its hypotonic aspect ("Asthenic") and conversely its hypertonic, tight character ("Strained"). For each characteristic, its appreciation is between 0 (normal) and 3 (very altered). After reading the adaptation of Aesop's fable, "Boree and the sun", recorded on the PRAAT software (version 6.1.03), two blind investigators who assessed the voice with a full number score between 0 and 15 .

The objective assessment of the voice was made by an acoustic recording of the patient's voice. To do so, he/she was first asked to produce a [a] on his normal voice, without forcing, holding this phoneme for as long as possible. Then he/she was asked to perform an upward siren on a [or] few seconds in order to get the most acute voice possible. This recording collected the following data: the mean (Fo) and maximum (Fo-max) fundamental frequency in $\mathrm{Hz}$, the maximum phonation time (MPT) in $\mathrm{s}$, the Jitter (change in the average fundamental frequency on the [a]) in $\%$, the Shimmer (variation of the fundamental intensity of the [a]) in $\%$ and the Harmonic/Noise Ratio (HNR). We have also chosen to use the Dysphonia Severity Index (DSI) [11] whose formula is calculated from the objective parameters for the study of the voice: $\mathrm{DSI}=(0.13 \mathrm{xMPT})$ $(0.0053 x$ Fo-max $)-(0.26 x k)-(1.18 x J i t t e r)-12.4$. We chose to use a constant $(\mathrm{k})$ as a minimum intensity for all patients $(\mathrm{k}=50 \mathrm{~dB}$, classically encountered intensity). Indeed, we did not want the possible differences between pre- and postoperative DSI to be correlated only with the variation in intensity-minimum, a highly variable acoustic parameter. A poor quality voice leads to a DSI $\leq-5$; a good quality voice $\geq+5$.

All the variables were collected during the preoperative consultation and repeated three months after surgery.

The distribution of patients between normal and impaired voice was achieved after construction of a composite score. The voice was considered impaired if there was an increase of at least 4 points of the VHI $10 \mathrm{and} /$ or an increase of at least 1 point of the GRBAS scale score and/or a decrease of at least 2 points of the DSI.

\section{Statistical considerations}

Comparisons of means were made using Wilcoxon test based on validation of the conditions of completion.

Comparisons of proportions were made by chi-2 tests.

The identification of predictors of voice quality was made by multivariate logistic regression after verification of the absence of colinearity and the stability of the model. Age was included in categorical form because of a non-linear relationship with voice quality.

A $p<0.05$ was considered significant. All statistical analyses were conducted using the R software (v. 3.5.3, www.r-project.org).

\section{Results}

\section{Comparisons of voice assessments before/after surgery.}

The mean VHI evolved from $3.39 \pm 5.40$ in preoperative to $2.90 \pm 5.29$ $(\mathrm{p}=0.62)$ in postoperative. The mean GRBAS score increased from 0.64 \pm 0.76 in preoperative to $0.73 \pm 0.85$ in postoperative $(\mathrm{p}=0.57)$. Finally, the mean DSI evolved from $8.47 \pm 1.15$ before surgery to $8.31 \pm 1.03$ after $(\mathrm{p}=0.42)$.

The mean of the postoperative values of the 59 patients with the different acoustic measurements were not significantly different from those preoperative: Fo had evolved from $157.06 \mathrm{~Hz}$ to $164.01(\mathrm{p}=0.36)$, the mean Jitter from 0.66 to $0.54 \%$ ( $\mathrm{p}=0.19$ ), the mean Shimmer from 8.70 to $7.70 \%(\mathrm{p}=0.19)$, the Fo-max from 495.35 to $471.93 \mathrm{~Hz}(\mathrm{p}-0.37)$ and the TMP from 15.56 to 14.19 seconds $(\mathrm{p}=0.19)$. Only HNR was significantly different in postoperative $(15.31 \pm 4.52 \mathrm{~dB})$ compared to its preoperative measure $(13.62 \pm 4.36 \mathrm{~dB})(\mathrm{p}=0.04)$.

The figure 3 represents changes in scores at the VHI10, GRBAS and DSI scales of our population after thyroid surgery.

Of the 59 patients included, 12 patients $(20.3 \%)$ answered in the affirmative to the question asked during the 3-month post-operative vocal check-up "Is your voice degraded compared to the pre-surgical one?" 


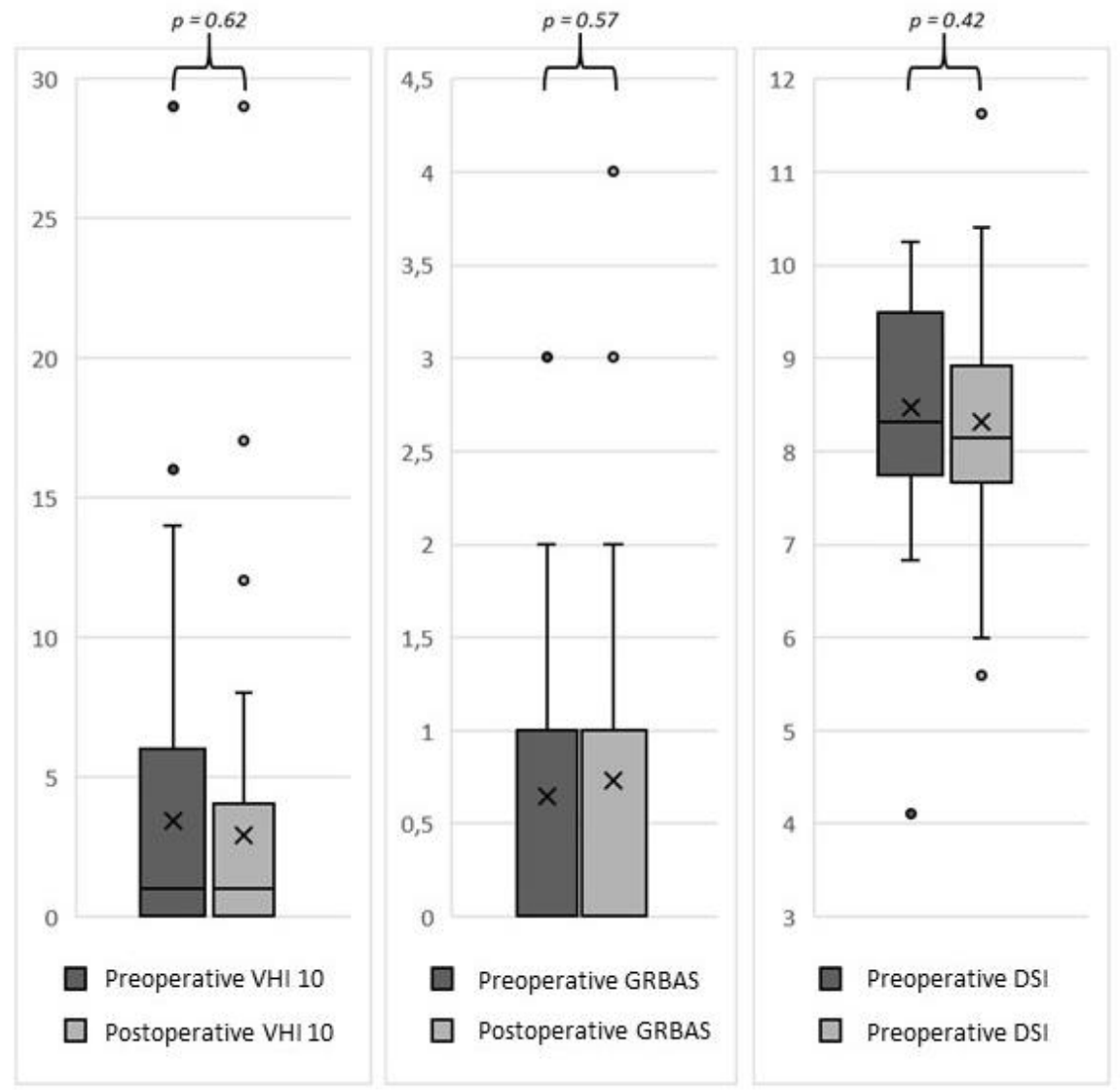

Figure 3. Evolution of VHI 10, GRBAS and DSI.

\section{Distribution of patients in altered/unaltered voice groups}

The distribution of patients using the composite vocal impairment score identified 14 patients with an impaired voice $(23.7 \%)$ three months after surgery. Of these 14 patients, one met all three outcomes (VHI 10, GRBAS and DSI), one patient two of the three criteria (VHI 10 and
GRBAS). The other 12 patients met only one criterion (one patient had an increase VHI $10 \geq$ to 2,10 an increase in GRBAS $\geq 2$ and finally the last patient had a decrease in his DSI score $\leq 2$ ). The characteristics of patients with and without voice impairment objectified by the chosen composite judgment criterion are listed in Table 2.

\begin{tabular}{|l|l|l|l|}
\hline & Unaltered voice & Altered voice & $p$ \\
\hline Mean age \pm SD $(\mathrm{yrs})$ & $\mathrm{N}=45$ & $\mathrm{~N}=14$ & \\
\hline Age by categories (yrs) $\mathrm{n}(\%)$ & $52.04 \pm 13.45$ & $61.53 \pm 15.25$ & $\mathbf{0 . 0 4 6}$ \\
$\quad<45$ & & & $\mathbf{0 . 0 4 7}$ \\
$45-55$ & $15(33.3)$ & $3(21.4)$ & \\
$55-65$ & $12(26.7)$ & $1(7.1$ & \\
$>65$ & $10(22.2)$ & $2(14.3)$ & \\
\hline Sex & $8(17.8)$ & $8(57.1)$ & \\
$\quad$ Females & $32(71.1)$ & $12(85.7)$ & \\
$\quad$ Males & $13(28.9)$ & $2(14,3)$ & \\
\hline Body mass index $\left(\mathrm{kg} / \mathrm{m}^{2}\right)$ & & & \\
$\quad<25$ & $19(42.2)$ & $8(57.1)$ & 0.717 \\
$\geq 25$ and $<30$ & $18(40.0)$ & $4(28.6)$ & \\
$\geq 30$ & $8(17.8)$ & $2(14.3)$ & \\
\hline Intensive vocal use at work: & & & \\
$\quad$ Yes & $27(84.4)$ & $7(100.0)$ & \\
No & $5(15.6)$ & $0(0.0)$ & \\
\hline Smoking: & & & \\
Yes & $12(26.7)$ & $0(0.0)$ & 0.053 \\
No & $33(73.3)$ & $14(100.0)$ & \\
\hline Mean preoperative VHI $10 \pm$ SD & $2.24 \pm 3.80$ & $7.07 \pm 7.89$ & $\mathbf{0 . 0 1 4}$ \\
\hline
\end{tabular}




\begin{tabular}{|c|c|c|c|}
\hline Mean postoperative VHI $10 \pm$ SD & $1.44 \pm 2.48$ & $7.57 \pm 8.56$ & 0.003 \\
\hline Mean preoperative GRBAS \pm SD & $0.71 \pm 0.73$ & $0.43 \pm 0.85$ & 0.088 \\
\hline Mean postoperative GRBAS \pm SD & $0.49 \pm 0.66$ & $1.50 \pm 0.94$ & $<0.001$ \\
\hline Mean preoperative DSI \pm SD & $8.37 \pm 1.13$ & $8.77 \pm 1.22$ & 0.392 \\
\hline Mean postoperative DSI \pm SD & $8.42 \pm 1.01$ & $7.95 \pm 1.02$ & 0.129 \\
\hline Postoperative Fo-max $(\mathrm{Hz}) \pm \mathrm{SD}$ & $490.47 \pm 145.52$ & $412.35 \pm 118.19$ & 0.06 \\
\hline $\begin{array}{l}\text { High preoperative VHI } 10(\geq 3) n(\%) \\
\text { Yes } \\
\text { No }\end{array}$ & $\begin{array}{l}12(26.7) \\
33(73.3)\end{array}$ & $\begin{array}{l}10(71.4) \\
4(29.6)\end{array}$ & 0.007 \\
\hline $\begin{array}{l}\text { High preoperative GRBAS }(\geq 1) \mathrm{n}(\%) \text { : } \\
\text { Yes } \\
\text { No }\end{array}$ & $\begin{array}{l}26(57.8) \\
19(42.2)\end{array}$ & $\begin{array}{l}4(28.6) \\
10(71.4)\end{array}$ & 0.109 \\
\hline $\begin{array}{l}\text { Voice Fatigue } \\
\text { Yes } \\
\text { No }\end{array}$ & $\begin{array}{l}6(13.3) \\
39(86.7)\end{array}$ & $\begin{array}{l}7(50.0) \\
7(50.0)\end{array}$ & 0.008 \\
\hline $\begin{array}{l}\text { «Has your voice deteriorated?» } \\
\text { Yes } \\
\text { No }\end{array}$ & $\begin{array}{l}3(6.7) \\
42(93.3)\end{array}$ & $\begin{array}{l}9(64.3) \\
5(35.57)\end{array}$ & $<0.001$ \\
\hline
\end{tabular}

Table 2. Comparison of populations "Unaltered Voice" and "Altered Voice" according to the composite judgment criterion.

SD: standard deviation

The other acoustic variables studied did not show a significant difference between the two groups (Fo, Jitter, Shimmer, MPT).

The surgical history, surgical indication, type of surgery, size of the larger thyroid nodule, resection or section of infra-hyoid muscles, pathological analysis and follow-up duration were not significantly different between the "unaltered voice" and "impaired" group.

Of the 59 patients included, 12 patients (20.3\%) answering in the affirmative to the question asked during the 3 -month post-operative vocal check-up "Is your voice degraded compared to the pre-surgical one?", 9 (75.0\%) voice impairment objectified by the composite judgment test chosen in this work. The only patient with an alteration of his voice objectified by all the elements of the composite judgment criterion did not complain of having a "degraded" voice at 3 months of surgery compared to his preoperative voice.

In the group of patients who answered negatively to the question "Is your voice degraded compared to pre-surgical?", 5 (10.6\%) of these 47 patients had vocal impairment using our composite endpoint as an endpoint. Thus, between these two groups, the difference in vocal alterations highlighted by the composite judging criterion was significant ( $\mathrm{p}<0.001)$.

\section{Multivariate determination of predictive factors of altered/unaltered voice}

Table 3 shows the results of the multivariate logistic regression model performed with age, sex, body mass index, preoperative VHI 10 score in categorical form, and type of surgery. Age $\geq 65$ (Odds ratio (OR): 17,4; $95 \%$ Confidence Interval (IC) $[1,6 ; 560,0], \mathrm{p}=0.04)$, preoperative $\mathrm{VHI} \geq$ 3 (OR: 9,5; IC [1.9; 66.4], $\mathrm{p}=0.011$ ) and thyroid re-intervention (OR: 75,8 ; IC [2.1;9777.8], $\mathrm{p}=0.037$ ) therefore emerged in our population as significant independent risk factors for vocal impairment.

\section{Discussion}

Our subjective and objective study of the voice showed that the vocal quality at 3 months of thyroid surgery with a complete neuromonitoring response at the end of the surgery was not significantly impaired compared to the preoperative situation. Our composite judgment criterion identified 14 patients $(23.7 \%)$ vocal impairment after surgery. The three independent risk factors for postoperative vocal impairment identified in our work were age $\geq 65$ years, AHI $10 \geq 3$ in preoperative and thyroid reintervention.
Very few studies presented results with intraoperative monitoring of lower and upper laryngeal nerves in such a population with subjective and objective evaluation criteria [12-14]. Grouping three scores including subjective and objective evaluation variables allowed us to prioritize sensitivity to specificity. The vocal degradation might therefore be overestimated allowing us to identify patients with an altered voice, whereas it was considered to be of good quality by the averages at VHI 10, GRBAS and DSI scores analyzed separately. Among the risk factors identified in our model, age was also described by Sahli et al. [15], as well as thyroid reintervention [16]. Calcifications of laryngeal cartilage, alteration of the laryngeal lining, or atrophy of laryngeal muscles accompanying aging have all been suggestions advanced to explain that age is an independent risk factor for vocal impairment after thyroid surgery [17]. Other studies have shown that sex, body mass index, lack of use of laryngeal neuromonitoring, thyroid tumor size, thyroid gland weight or postoperative hypocalcemia were risk factors for altering vocal quality at a distance from surgery $[18,19]$, which we did not find in our work.

According to our composite score, 14 patients (23.7\%) had altered their voices at 3 months of their thyroid surgery, which is classically found at a distance from thyroid surgery $[2,20]$. However, unlike these studies, these vocal changes did not appear to be possible to be attributed to lesions of the lower or higher laryngeal nerves. To explain this large number of patients with altered voices but functional nerves according to the neuromonitoring, several reasons could be put forward (that can be limitations of our study). The combination of subjective and objective variables to detect impaired voices further improved sensitivity, compared to other studies using only subjective evaluation criteria may be one possible explanation $[2,8,12,13]$. The short time between surgery and postoperative ENT evaluation at 3 months also overestimated the percentage of post-thyroid vocal impairment. This interval had been retained in order to minimize the number of patients lost of view. In addition, selection bias related to the inclusion of surgically operated patients in a referral hospital could explain this high percentage of impaired voices. Indeed, the preoperative mean VHI 10 was measured at 3.39 , knowing that a normal VHI 10 according to the scientific literature is less than 2.83 [21]. However, we have shown that a preoperative VHI $10 \geq 3$ was a risk factor of vocal impairment. Thus our population did not have a voice considered normal in preoperative. Finally, the method of assessing the functional integrity of EBULN could be discussed. The 
electromyography of the cricothyroid muscle is the gold standard to ensure the proper functioning of the ipsilateral EBULN. However, this difficult-to-access technique is invasive and EBULN neuromonitoring at $1 \mathrm{~mA}$, according to the scientific literature, is reliable for highlighting a complete nerve injury [7, 22]. But enough for a slight impairment?

No significant differences were found between the acoustic data before and after surgery other than an increase of HNR. This increase would even suggest an improvement in the patient's voice. Other studies have found alterations in Fo, Fo-max, Shimmer, MPT or but none monitored the EBULN [23, 24]. Thus, these acoustic changes could be attributed to damage to this nerve branch $[25,26]$. The Engelsman et al. study monitoring the lower and upper laryngeal nerves did not object to any significant difference between the different acoustic parameters studied [14].

The perspective of this study is to find out if the voice impairment is linked with an EBULN injury that can't be seen with the neuromonitoring or with another reason. Performing a perioperative electromyography of the cricothyroid muscle is too difficult but the technological improvement of the NIM with lower level of detection of the cricothyroid muscle May precise it.

\section{Conclusions}

In the absence of laryngeal nerve injury (lower and upper) objectified by intraoperative neuromonitoring, post-thyroidectomy vocal quality was not significantly impaired compared to preoperative. However, in our more sensitive model (combined score), 23.7\% of patients undergoing thyroid surgery would have an alteration of their voice. The three independent risk factors for postoperative vocal impairment found in our work were age $\geq 65$ years, VHI $10 \geq 3$ in preoperative and thyroid reintervention.

\section{Conflict of interests}

None

\section{Acknowledgements}

We would like to thank Drs. PEROUSE and COULOMBEAU (ENT) for their invaluable assistance in the acoustic approach to the voice and the paramedic team of the ENT consultation at the hospital for their contribution to the work of data collection.

\section{References}

1. Le Bail M, Or ZA. (2016). Atlas des variations de pratiques médicales. Recours à dix interventions chirurgicales. Paris: Institut de Recherche et de Documentation en Economie de la Santé (I.R.D.E.S.).

2. Borel F, Christou N, Marret O, Mathonnet M, Caillard C, et al. (2018). 0 Long-term voice quality outcomes after total thyroidectomy: a prospective multicenter study. Surgery;163:796800 .

3. Jeannon JP, Orabi AA, Bruch GA, Abdalsalam HA, Simo R. (2009). Diagnosis of recurrent laryngeal nerve palsy after thyroidectomy: a systematic review. Int J Clin Pract; 63:624-629.

4. Dralle H, Sekulla C, Lorenz K, Brauckhoff M, Machens A. (2008). Intraoperative monitoring of the recurrent laryngeal nerve in thyroid surgery. World J Surg; 32:1358-66.

5. Lifante JC, McGill J, Murry T, Aviv JE, Inabnet WB, 3rd. (2009). A prospective, randomized trial of nerve monitoring of the external branch of the superior laryngeal nerve during thyroidectomy under local/regional anesthesia and IV sedation. Surgery;146:1167-1173.

6. Darr EA, Tufano RP, Ozdemir S, Kamani D, Hurwitz S, Randolph G. (2014). Superior laryngeal nerve quantitative intraoperative monitoring is possible in all thyroid surgeries. Laryngoscope; $124: 1035-1041$.

7. Barczynski M, Randolph GW, Cernea CR, Dralle H, Dionigi G, et al. (2013). External branch of the superior laryngeal nerve monitoring during thyroid and parathyroid surgery: International Neural Monitoring Study Group standards guideline statement. Laryngoscope;123 Suppl 4:S1-14.

8. Borel F, Tresallet C, Hamy A, Mathonnet M, Lifante JC,et al. (2020). Self-assessment of voice outcomes after total thyroidectomy using the Voice Handicap Index questionnaire: Results of a prospective multicenter study. Surgery;167:129-136.

9. Rosen CA, Lee AS, Osborne J, Zullo T, Murry T. (2004). Development and validation of the voice handicap index-10. Laryngoscope; $114: 1549-1556$.

10. Hirano M. (1981). Clinical examination of voice. New York. Springer Verlag; 81-84.

11. Wuyts FL, De Bodt MS, Molenberghs G, Remacle M, Heylen L, et al. (2000). The dysphonia severity index: an objective measure of vocal quality based on a multiparameter approach. Journal of speech, language, and hearing research: JSLHR; 43:796-809.

12. Tedla M, Chakrabarti S, Suchankova M, Weickert MO. (2016). Voice outcomes after thyroidectomy without superior and recurrent laryngeal nerve injury: VoiSS questionnaire and GRBAS tool assessment. Eur Arch Otorhinolaryngol; 273:45434547.

13. Wojtczak B, Sutkowski K, Kaliszewski K, Forkasiewicz Z, Knychalski B, et al.(2018). Voice quality preservation in thyroid surgery with neuromonitoring. Endocrine; 61:232-239.

14. Engelsman AF, Warhurst S, Fraser S, Novakovic D, Sidhu SB. (2018). Influence of neural monitoring during thyroid surgery on nerve integrity and postoperative vocal function. BJS open; $2: 135$ 141.

15. Sahli Z, Canner JK, Najjar O, Schneider EB, Prescott JD,et al. (2019). Association Between Age and Patient-Reported Changes in Voice and Swallowing After Thyroidectomy. Laryngoscope; 129:519-524.

16. Minni A, Rosati D, Cavaliere C, Ralli M, Sementilli G, et al. (2019). Total Versus Completion Thyroidectomy: A Multidimensional Evaluation of Long-Term Vocal Alterations. Ear Nose Throat J:145561319886156.

17. Papadakis CE, Asimakopoulou P, Proimos E, Perogamvrakis G, Papoutsaki E, et.al (2017). Subjective and Objective Voice Assessments After Recurrent Laryngeal Nerve-Preserved Total Thyroidectomy. $J$ Voice; 31:515 e15- e21.

18. Misono S, Yueh B, Stockness AN, House ME, Marmor S. (2017). Minimal Important Difference in Voice Handicap Index-10. JAMA otolaryngology-- head \& neck surgery;143:1098-1103.

19. Hakkesteegt MM, Wieringa MH, Brocaar MP, Mulder PG, Feenstra L. (2008). The interobserver and test-retest variability of the dysphonia severity index. Folia Phoniatr Logop;60:86-90.

20. Lee DY, Lee KJ, Hwang SM, Oh KH, Cho JG, et al. (2017). Analysis of Temporal Change in Voice Quality After Thyroidectomy: Single-institution Prospective Study. $J$ Voice;31:195-201.

21. Arffa RE, Krishna P, Gartner-Schmidt J, Rosen CA. (2012). Normative values for the Voice Handicap Index-10. $J$ Voice; 26:462-465.

22. Naytah M, Ibrahim I, da Silva S. (2019). Importance of incorporating intraoperative neuromonitoring of the external branch of the superior laryngeal nerve in thyroidectomy: A review and meta-analysis study. Head Neck; 41:2034-2041.

23. Lang BH, Wong CK, Ma EP. (2016). A systematic review and meta-analysis on acoustic voice parameters after uncomplicated thyroidectomy. Laryngoscope;126:528-537. 
24. Soylu L, Ozbas S, Uslu HY, Kocak S. (2007). The evaluation of the causes of subjective voice disturbances after thyroid surgery. Am J Surg;194:317-322.

25. Roy N. (2011). Denervation of the external branch of the superior laryngeal nerve: laryngeal and phonatory features. Curr Opin Otolaryngol Head Neck Surg;19:182-187.
26. Barczynski M, Konturek A, Stopa M, Honowska A, Nowak W. (2012). Randomized controlled trial of visualization versus neuromonitoring of the external branch of the superior laryngeal nerve during thyroidectomy. World J Surg;36:1340-1347.
This work is licensed under Creative Commons Attribution 4.0 License

\section{To Submit Your Article Click Here: Submit Manuscript}

DOI: $10.31579 / 2692-9562 / 025$
Ready to submit your research? Choose Auctores and benefit from:

* fast, convenient online submission

* rigorous peer review by experienced research in your field

* rapid publication on acceptance

* authors retain copyrights

* unique DOI for all articles

* immediate, unrestricted online access

At Auctores, research is always in progress.

Learn more www.auctoresonline.org/journals/journal-of-clinicalotorhinolaryngology 